Al Qalam: Jurnal Ilmiah Keagamaan dan Kemasyarakatan

Vol. 13, No. 2, 2019

P-ISSN: 1907-4174; E-ISSN: 2621-0681

\title{
PERSOALAN OTENTISITAS HADIS PERSPEKTIF IGNAZ GOLZIHER
}

\author{
Oleh: \\ Syarifuddin \\ STIQ Amuntai, Kalimantan Selatan, Indonesia \\ syarifuddin.stiq@gmail.com \\ Moh. Zaiful Rosyid \\ IAIN Madura, Indonesia \\ zaifulrosyid@gmail.com
}

\begin{abstract}
Abstrak
Hadis yang diwujudkan pada bentuk nyata dalam kehidupan, sabda, perilaku dan sikap Nabi terhadap segala sesuatu, terkadang menjadi hukum tersendiri yang tidak ditemukan dalam al-Qur'an. Keberadaan hadis yang sangat sentral dikalangan umat muslim menjadi sasaran tersendiri bagi musuh-musuh Islam (diantaranya kalangan orientalis) untuk meruntuhkan kepercayaan akan pedomannya. Pengkajian dan penelitian hadis terus dilakukan untuk menjadi dasar dalam meragukan validitas isi hadis tersebut, Goldziher sebagai salah satu tokoh orientalis yang melakukan kajian tentang hadis dengan terus menggempur kesahihan hadis dengan meragukan otentisitas hadis Nabi.
\end{abstract}

Kata Kunci: Hadits, orientalis, Ignaz Golziher

\section{Abstract}

The hadith is manifested on form real in life, word, behaviours and attitude of the Prophet towards all things, sometimes its own law that is not found in the Qur'an. The existence of hadith which a central among Muslims became targets for Islam's enemies (including orientalists) to undermine its guidelines. The Study and research of the hadith continues to be done as basis for doubting the validity of the of the hadith's, Goldziher as one of the oriental figures who did conducted a study of hadith by continously storming the validity of the hadith with doubting authenticity of the prophet's hadith.

Keywords: Hadith, orientalist, Ignaz Golziher

Al Qalam: Jurnal Ilmiah Keagamaan dan Kemasyarakatan Vol. 13, No. 2, Juli-Desember 2019 


\section{A. Pendahuluan}

Hadis Nabi diyakini oleh mayoritas umat Islam sebagai bentuk ajaran yang paling nyata dan merupakan realisasi dari ajaran Islam yang terkandung dalam al-Qur'an. Dalam hubungan antara keduanya, hadis berfungsi sebagai penjelas al-Qur'an. Interpretasi terhadap petunjuk Allah SWT diwujudkan dalam bentuk nyata dalam kehidupan, sabda, perilaku dan sikap Nabi terhadap segala sesuatu, terkadang menjadi hukum tersendiri yang tidak ditemukan dalam al-Qur'an.

Karena sedemikian sentralnya keberadaan hadis Nabi, banyak musuhmusuh Islam berupaya meruntuhkan ajaran Islam dengan cara mengkaji dan meneliti hadis dengan satu tujuan untuk meragukan dasar-dasar validitas hadis sebagai dalil/ dasar argumentasi. Penelitian dan kajian-kajian yang dilakukan oleh musuh-musuh Islam (diantaranya sebagian dilakukan oleh orientalis) yang sebenarnya mengajak umat Islam untuk meragukan kebenaran dari hadis tersebut. Dengan diragukannya hadis-hadis yang ada dalam kitab-kitab hadis karya ulama masa lalu, maka robohlah sudah satu pilar agama Islam. Sehingga umat Islam tidak memiliki kesatuan atau keseragaman dalam memahami alQur'an dan lebih jauh dalam mengaplikasikan ajaran-ajaran syari'at Islam tentunya, inilah tujuan utama kegiatan orientalis dalam mengkaji hadis.

Secara bahasa kata orientalisme (orientalism) diambil dari dua kata orient dan ism. Kata orient berarti direction of rising sun (arah terbit matahari). Sedangkan secara letak atau geografi, kata orient berarti dunia timur dan secara etnologi artinya bangsa-bangsa timur. Secara luas, kata orient juga bermakna wilayah yang membentang dari kawasan timur berdekatan (Turki dan sekitarnya) hingga timur jauh (Jepang, Korea, Cina) dan Asia Selatan hingga republik-republik Muslim bekas Uni Soviet, serta kawasan Timur Tengah hingga Afrika Utara. ${ }^{1}$ Berikutnya isme atau isme yang mempunyai makna

\footnotetext{
${ }^{1}$ Idri, Hadis dan Orientalis, h. 1.
} 
aliran, pendirian, ilmu, paham, keyakinan, dan sistem. ${ }^{2}$ Jadi secara etimologi kata orientalis bisa dimaknai sebagai ilmu tentang ketimuran atau studi tentang dunia timur.

Edwar Said mengatakan ada tiga pengertian dasar terkait dengan orientalisme: 1) sebuah cara kedatangan yang berhubungan dengan bangsabangsa timur berdasarkan tempat khusus timur dan pengalaman barat eropa; 2) sebuah gaya pemikiran yang berdasarkan antologi dan epistemologi barat pada umumnya; dan 3) sebuah gaya barat untuk mendominasi, membangun kembali, dan mempunyai kekuasaan terhadap timur. ${ }^{3}$ Dari beberapa pengetian tersebut bisa disederhanakan bahwa orientalisme adalah orang-orang yang menkaji tentang dunia timur.

Orientalis merupakan suatu perhimpunan yang anggotanya fokus mengkaji Alquran dan sunnah. ${ }^{4}$ Para orientalis barat memulai kajian teologi Islam sejak awal abad ke-19 Masehi. $^{5}$ Setelah bangsa-bangsa Eropa menaklukkan hampir seluruh dunia Islam. Dengan berbekal manuskrip karya para ulama dan ilmuan muslim mereka bawa ke Eropa dan mereka mulai mempelajari, mengkaji satu persatu khazanah intelektual Islam.

Untuk mengetahui bahwa seseorang itu orientalis atau bukan dapat dilihat dari sudut pandangnya dalam mengkaji dunia timur, tidak bisa dilihat dari aspek geografis pengkaji atau kajiannya semata. Oleh karena itu orientalis adalah orang yang menkaji dunia timur (Islam) berdasarkan logika ontologis dan epistemologis Barat, tidak masalah apakah ia orang barat atau bukan, Muslim atau non-muslim. Namun lazimnya predikat orientalis disandingkan kepada orang-orang barat yang mempunyai minat mengkaji Islam khususnya dan dunia ketimuran umunnya.

\footnotetext{
${ }^{2}$ Idri, h. 1.

${ }^{3}$ Idri, h. 1.

${ }^{4}$ Hati-hati!! Bahaya Tokoh ORIENTALIS - Ustadz Adi Hidayat.

${ }^{5}$ Arif, Orientalis \& diabolisme pemikiran, h. 47-48.
} 


\section{B. Riwayat Hidup Ignaz Goldziher}

Sebelum membahas lebih jauh mengenai pandangan Goldziher terhadap hadis, maka penulis uraikan biografinya terlebih dahulu. Ignaz Goldziher dilahirkan pada 22 Juni 1850 di sebuah kota di Hungaria dari sebuah keluarga Yahudi terpandang dan memiliki pengaruh, ${ }^{6}$ meninggal pada tahun $1921 .^{7}$ Goldziher terlatih dalam bidang pemikiran sejak usia dini. Dalam usia 5 tahun, dia mampu membaca teks Bibel dalam bahasa Ibrani. Pada umur enam belas tahun ia sudah belajar Bahasa timur, terutama Persia dan Turki. ${ }^{8}$ Pendidikannya dimulai dari Universitas Budapest, Hungaria, kemudian dilanjutkan di Berlin pada tahun 1869. hanya satu tahun disana, ia pindah ke Leipzig University, Jerman. Di bawah asuhan Flesser, salah satu guru besar orientalisme di universitas tersebut, Goldziher kemudian memperoleh gelar dokotral tingkat pertama tahun 1870 dengan risalah "Penafsir Taurat yang berasal dari Tokoh Yahudi abad tengah" pada usia 19 tahun. ${ }^{9}$

Sebagai seorang orientalis yang gigih, ia berusaha menciptakan keresahan umat Islam dengan mengeluarkan pemikiran-pemikiran yang membahayakan bagi umat Islam, seperti menggoyang kebenaran hadis Nabi Muhammad SAW, maka karya-karyanya menjadi sangat berbahaya, terutama berita kebohongan dan kebodohan yang dapat menciptakan permusuhan terhadap Islam. Setelah mengenal biografi tokohnya secara lebih jelas, maka penulis akan menjelaskan lebih jauh mengenai pemikirannya.

Goldziher juga dikenal ahli dalam upaya izharul Islam atau berpurapura Islam dan ia pernah belajar secara resmi di universitas al-azhar Messir dan talaqqi (belajar non formal tatap muka) dengan syaikh di kairo. Goldziher pernah berguru denganbeberapa syaikh al-azhar seperti: Syaikh al-Asmawi,

\footnotetext{
${ }^{6}$ A. Mannan Buchari, Menyingkap Tabir Orientalisme, h. 19.

${ }^{7}$ AlMakin, Antara Barat dan Timur, h. 89.

${ }^{8}$ AlMakin, h. 89.

${ }^{9}$ Zainuddin, "Persoalan Otentisitas Hadits," h .266.
} 
Syaikh Mahfuz al-Maghribi, Syaikh Sakka dan beberapa syaikh al-azhar lainnya. ${ }^{10}$

Karya tulisnya sebagian besar membahas masalah-masalah keislaman yang banyak diplubisir dalam bahasa Jerman, Inggris dan Perancis, bahkan sebagian karyanya diterjemahkan ke dalam bahasa Arab, dan yang paling berpengaruh dari karya tulisnya adalah buku Muhammadanische Studien, dimana ia menjadi sumber rujukan utama dalam penelitian Hadis di Barat, bahkan bukunya menjadi "kitab suci" di kalangan orientalis. ${ }^{11}$ Golziher telah banyak menghasilkan banyak karya dalam berbagai bidang, baik akidah, fikih, tafsir, hadis, maupun sastra. Hasil karya kreatifnya diantaranya: ${ }^{12}$

1. Muhammedanisnche Studien (Studi Pengikut Muhammad, 2 jilid, 1889-1890)

2. Vorlesungen Uber den Islam (Introduction to Islamic Theology and Law)

3. Muslim Studies

4. Methology Among The Hebrews And Its Historical Development

5. On The History of Grammar Among The Arabs

6. Zahiris: Their Doctrine and Their History, a Contribution diterbitkan pada tahun 1884 .

7. Short History of Classical Arabic Literature

8. Le Dogme et Les Lois de L'Islam (The Principle of Law is Islam)

9. Etudes Sur La Tradition Islamique, dan karya-karya tulis lainnya.

10. Die Riechtungen der islamischen Koranauslegung (Mazhab-mazhab Tafsir dalam Islam, Leiden, 1920)

Pemikiran Goldziher ternyata berdampak sangat luas terhadap seluruh kajian-kajian tentang Islam. Pengaruhnya bukan saja di kalangan orientalis saja melainkan juga di kalangan pemikir muslim. Selain itu, kajian tentang hadis

\footnotetext{
${ }^{10}$ Artawijaya, Jaringan Yahudi Internasional di Nusantara, h. 176.

${ }^{11}$ Mustofa Yaqub, Kritik Hadits, h..8.

${ }^{12}$ Zainuddin, "Persoalan Otentisitas Hadits," h. 271.
} 
sangat dikenal oleh kalangan pemikir muslim mengingat dalam pemikiran tersebut Goldziher banyak meragukan isi hadis dengan segala teori yang ia gunakan.

Menurut Muhammad Mustafa Azami, Goldziher barangkali adalah orientalis yang melakukan kajian tentang Hadis. Baru kemudian disusul oleh orientalis-orientalis yang lainnya seperti J. Schacht, Juynboll dan lain-lain. Ignaz Goldziher berkesimpulan bahwa apa yang disebut Hadis itu diragukan otentisitasnya sebagai sabda Nabi SAW. dan dia menuduh bahwa penelitian Hadis yang dilakukan oleh ulama klasik tidak dapat dipertanggungjawabkan secara ilmiah karena kelemahan metodenya. Hal itu karena ulama lebih banyak menggunakan metode kritik sanad dan kurang menggunakan kritik matan. ${ }^{13}$

Permasalahan tersebut terus berlanjut, Goldziher terus menggempur para pemikir muslim dengan terus meragukan hadis yang dianggapnya kurang efektif dengan kritik sanad yang digunakan. Menurutnya ulama hadis kurang menggunakan kritik matan dianggap hadis-hadis yang ada saat diragukan kebenarannya secara ilmiah.

Goldziher merupakan tokoh yang menjadi fondasi dasar kajian Islam di barat dalam bidang sejarah, terutama perkembangan Islam awal, bidang hadis, juga Bahasa arab, sastra (adab), tafsir, teologi (kalam) dan hokum (fiqh). ${ }^{14}$

Hal inilah yang melatarbelakangi karya Muhammad Mustafa Azami dalam tentang Hadis Nabawi dan Sejarah Kodifikasinya, yaitu ia menyanggah pendapat-pendapat para orientalis dengan mendiskusikannya secara ilmiah, dengan menangkis kepalsuan-kepalsuan mereka dan mengkritik pendapatpendapat mereka dengan argumen yang kuat, serta meruntuhkan sumbersumber yang lemah, yang dijadikan pegangan oleh mereka, berikut menyingkap

\footnotetext{
${ }^{13}$ Herfin Fahri, "Kontroversi Tentang Otentisitas Hadits," h.81.

${ }^{14}$ AlMakin, Antara Barat dan Timur, h. 90.
} 
tabir kekeliruan mereka dalam memahami sejumlah sumber rujukan dalam bahasa Arab. ${ }^{15}$

\section{Pandangan Hadis Ignaz Goldziher}

1. Kodifikasi Hadis

Diskursus tentang otentisitas hadis merupakan salah satu hal yang sangat krusial dan kontroversial karena perbedaan dengan alquran yang telah mendapatkan garansi. Sebagaimana firman Allah Swt. dalam ayatnya yang berbunyi:

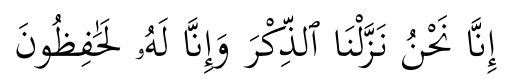

Artinya: Sesungguhnya Kami-lah yang menurunkan Al Quran, dan sesungguhnya Kami benar-benar memeliharanya.[Quran 15:9]

Goldziher, sebagai orientalis yang kritis, tak lupa menyoroti point ini dengan menganggap negatif keberadaan hadis. Walaupun dia dikenal lebih skeptis dari pada Alois Sprenger (kritikus hadis pertama kali) dengan karyanya Uber Das Traditionsweser Bei Dai Arabern (1856) dan Sir William Munir dengan karyanya Life of Mahomet, namun dalam beberapa hal, Goldziher mampu memberikan penilaian seputar eksistensi dan validitas hadis. ${ }^{16}$

Goldziher menyimpulkan bahwa sebagian besar hadis merupakan akibat dari perkembangan Islam secara religious, historis, dan sosial selama dua abad pertama. Hadis-hadis itu tidak dianggap sebagai dokumen sejarah pertumbuhan Islam, tetapi lebih sebagai refleksi dari berbagai kecenderungan yang ada dalam masyarakat Islam selama tahap-tahap perkembangannya.

Dengan demikian, menurut Goldziher, tidak hanya hukum dan adat kebiasaan, tetapi juga doktrin politik dan teologi pun mengambil bentuk dalam hadis. Apa saja yang dihasilkan Islam sendiri atau dipinjam dari unsur luar diberi tempat dalam hadis. Bahkan beberapa bagian, baik dari perjanjian lama maupun perjanjian baru, kata-kata dari rabi, kutipan dari Injil Aporki, doktrin

\footnotetext{
${ }^{15}$ Azami M.M, Hadis Nabawi dan Sejarah Kodifikasinya, h.x.

${ }^{16}$ Mustofa Yaqub, Kritik Hadits, h. 273.
} 
para filsuf Yunani, ditampilkan kembali dan dinyatakan sebagai sabda-sabda Nabi. ${ }^{17}$ Dengan demikian dapat disimpulkan bahwa pandangan-pandangan Goldziher tentang hadis adalah sebagai berikut:

1) Sebagian besar hadis merupakan hasil perkembangan Islam di bidang politik dan sosial.

2) Para sahabat dan tabi'in berperan dalam pemalsuan hadis.

3) Rentang waktu dan jarak yang jauh dari masa Rasulullah SAW. membuka peluang bagi para tokoh berbagai aliran untuk membuat hadis dengan tujuan memperkuat aliran mereka. Bahkan, tidak ada satu pun aliran, baik yang bersifat teoritis maupun praktis, yang tidak mengukuhkan pendapatnya dengan hadis- hadis yang tampaknya asli dalam bidang Aqidah, Fiqih, atau politik.

4) Sudut pandang para kritikus dari kalangan umat Islam berbeda dengan sudut pandang para kritikus asing (non-muslim) yang tidak menerima kebenaran banyak hadis yang diakui benar oleh umat Islam.

5) Ia menggambarkan enam kitab hadis sebagai himpunan berbagai macam hadis yang tercecer, yang oleh para penghimpunnya dinilai sebagai hadis shahih. ${ }^{18}$

\section{Kritik Matan}

Goldziher mengakui bahwa kritik hadis sebenarnya telah dilakukan sejak dahulu, namun menurutnya kritik-kritik tersebut tidak dapat dipertanggungjawabkan secara ilmiah, hal itu karena metode yang digunakannya lemah. Para ulama terdahulu, menurut Goldziher lebih banyak menggunakan kritik sanad dan mengabaikan kritik matan. Dan kritik semacam ini, menurut Goldziher hanya mampu mengeluarkan sebagian hadis palsu saja. ${ }^{19}$ Hadits, h.34-35.

17 Ali, Teori Common Link G.H.A. Juynboll: Melacak Akar Kesejarahan

${ }^{18}$ Muhammad, Hadis Nabi Sebelum Dibukukan, hlm.299-301. Hadits, h.116.

19 Ali, Teori Common Link G.H.A. Juynboll: Melacak Akar Kesejarahan 
Goldziher kemudian menawarkan metode kritik baru yaitu kritik pada matan. Menurutnya kritik matan hadis itu mencakup berbagai aspek seperti politik, sains, sosio kultural dll. Goldziher menyatakan bahwa redaksi hadis yang diriwayatkan oleh perawi-perawi hadis dinilai tidak akurat, karena mereka lebih menitikberatkan pada aspek makna hadis sehingga para ahli bahasa merasa enggan menerima periwayatan hadis disebabkan susunan bahasanya tergantung pada pendapat perawinya. ${ }^{20}$

Sebenarnya para ulama' telah melakukan kritik matan tersebut, namun yang dimaksud Goldziher adalah kritik matan yang mencakup berbagai aspek seperti politik, sains, sosio kultural dan sebagainya.

Metode ahli hadis dinilai lemah oleh orang-orang orientalis dan orangorang yang sependapat dengan mereka, karena itu mereka menolak metode itu dan membuat metode sendiri yang kemudian dikenal dengan dengan metode "metode kritik matan hadis". ${ }^{21}$ Salah satu kritiknya antara lain ia alamatkan kepada Bukhari. Menurutnya pemilik kitab Shahih ini hanya melakukan kritik sanad dan mengabaikan kritik matan. Akibatnya setelah dilakukan penelitian oleh Goldziher, salah satu hadis yang ada dalam sahihnya itu ternyata palsu. Hadis yang dimaksud adalah hadis yang diriwayatkan oleh al-Zuhri yang berbunyi:

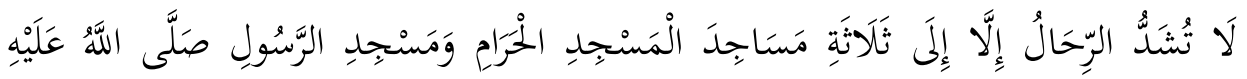

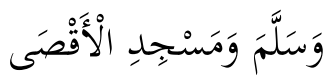

Artinya: Tidak diperintahkan pergi kecuali menuju tiga masjid, Masjid Al-

Haram, Masjid Nabawi, dan Masjid Al-Aqsa.

Menurut Goldziher hadis ini merupakan pesanan Abdul Malik bin Marwan, seorang khalifah dari Dinasti Umayah di Damaskus yang merasa khawatir apabila Abdullah ibn Zubair, yang memproklamirkan sebagai seorang

\footnotetext{
${ }^{20}$ Zainuddin, "Persoalan Otentisitas Hadits," h.283.

${ }^{21}$ Azami M.M, Hadis Nabawi dan Sejarah Kodifikasinya, h.608.
} 
khalifah di Makkah, mengambil kesempatan dengan menyuruh orang-orang Syam yang melakukan ibadah haji di Makkah untuk berbaiat kepadanya. Karenanya, Abdul Malik berusaha agar orang-orang Syam tidak lagi pergi ke Makkah, tetapi cukup hanya pergi ke Qubah al-Shakhra di Al-Quds yang pada saat itu berada pada wilayah Syam. Untuk itulah ia memerintahkan Al-Zuhri untuk membuat hadis sebagaimana di atas. ${ }^{22}$

Menurutnya "Abd Al-Malik bin Marwan merasa khawatir apabila orang-orang Syam yang pergi haji ke Mekkah itu melakukan baiat kepada 'Abdullah bin al-Zubair. Karena itu ia berusaha agar orang-orang dapat melakukan haji di Qubah al-Shakhra di Qudus (Jerussalem) sebagai ganti dari pergi haji ke Mekkah. ${ }^{23}$

Hal ini dapat disimpulkan bahwa, menurut Goldziher, hadis itu adalah buatan ulama' (Al-Zuhri) meski ia ada dalam kitab sahih Bukhari. Menurut Yaqub, dengan pendapatnya itu tidak terlalu sulit untuk diidentifikasi bahwa Goldziher bertujuan untuk meruntuhkan kepercayaan umat Islam terhadap Imam Bukhari yang kredibilitasnya telah diakui kaum Muslimin, sehingga pada akhirnya semua kitab hadis dalam sahihnya tidak dipakai lagi oleh kaum muslimin. Kemudian setelah Bukhari, maka imam-imam hadis pun akan ia bantai satu persatu, sehingga hilanglah hadis dari peredaran dan hilang pula salah satu pilar agama Islam.

\section{Metode Otentifikasi Hadis}

Menurut M.M. Azami, apabila berbicara mengenai hadis Nabi, maka kita juga perlu mengkaji sikap alquran terhadap hadis, serta sejauh mana hadis memperoleh perhatiannya. Apabila keluhuran nilai hadis dan kedudukannya dalam Islam sudah ketahui, maka kita perlu mengkaji cara-cara yang ditempuh kaum muslimin dalam memelihara hadis tersebut. ${ }^{24}$ Ayat-ayat alquran banyak

\footnotetext{
${ }^{22}$ Azami M.M, Dirasah fi al-Hadits an-Nabawi wa Tarikh Tadwinih, h.457.

${ }^{23}$ Azami M.M, Hadis Nabawi dan Sejarah Kodifikasinya, h.608.

${ }^{24}$ Azami M.M, h.7.
} 
memberikan penjelasan tentang peran dan kedudukan hadis dalam Islam. Informasi yang didapat dari alquran antara lain:

Surat Al-Nahl ayat 44, berisikan tentang peran dari Rasulullah sebagai mubayyin, untuk memberikan penjelasan bagi umat manusia atas alquran, ${ }^{25}$ berbunyi:

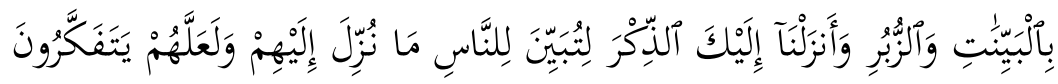

Artinya: keterangan-keterangan (mukjizat) dan kitab-kitab. Dan Kami turunkan kepadamu Al Quran, agar kamu menerangkan pada umat manusia apa yang telah diturunkan kepada mereka dan supaya mereka memikirkan,[Quran 16:44]

Dilihat dari ruang lingkup dan jangkauan alquran serta keterbatasan manusia dalam memahami petunjuk alquran, nabi Muhammad Saw. mendapat legitimasi dari Allah Swt. untuk menjelaskan dan merinci ayat-ayat alquran dan menjawab serta menyelesaikan permasalahan umat yang tidak ditemukan jawabannya di dalam alquran. Hal tersebut tertuang dalam ayatnya yang berbunyi:

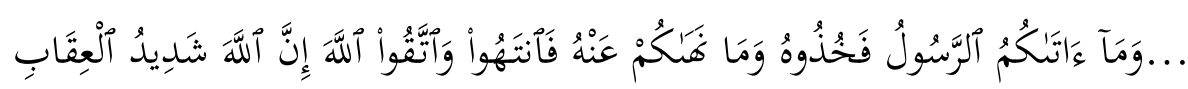

Artinya: ... Apa yang diberikan Rasul kepadamu, maka terimalah. Dan apa yang dilarangnya bagimu, maka tinggalkanlah. Dan bertakwalah kepada Allah. Sesungguhnya Allah amat keras hukumannya. [Quran $59: 7] .^{26}$

Metode yang digunakan oleh para ahli hadis dalam menetapkan otentisitas hadis adalah dengan meneliti sanad dan matan hadis. Untuk dapat

${ }^{25}$ Suryadi dan Suryadilaga, Metodologi Penelitian Hadis, h.8.

${ }^{26}$ Isa H.A. Salam dan Bustamin (last), Metodologi Kritik Hadis, h.12. 
memahami metodologi yang mereka gunakan, terlebih dahulu harus memahami pengetahuan dasar seputar hadis. ${ }^{27}$

Menurut M.M. Azami, sebelum membahas tentang sejauh mana hadis dapat dipertanggungjawabkan otentisitasnya, M.M. Azami juga menjelaskan tentang kapan penulisan hadis dimulai, membahas cara penyebaran hadis dan permasalahan sanad hadis, yang mana hal-hal tersebut merupakan bukti historis dari keotentikan hadis.

1. Penulisan Hadis Nabawi

Pendapat yang dominan di kalangan sarjana dan ilmuwan adalah hadis-hadis hanya disebarkan melalui lisan sampai akhir abad pertama hijriah. Sedangkan yang pertama kali mempunyai ide untuk menulis hadis adalah Khalifah Umar bin Abdul Aziz, di mana beliau mengirim surat kepada Abu Bakar bin Muhammad bin Hazm, yang mengatakan, "Periksalah dan tulislah semua hadis-hadis Nabi, atau hadis tentang umrah; karena saya khawatir hal itu akan punah. Khalifah memberikan tugas kepada Ibnu Syihab Al-Zuhri untuk mengumpulkan dan menuliskan hadis. ${ }^{28}$ Dengan demikian secara tidak langsung Ibnu Syihab al-Zuhrilah yang pertama melaksanakan instruksi tersebut, sehingga ia dikenal sebagai orang pertama yang melakukan kodifikasi hadis.

\section{Penyebaran Hadis (Tahammul al-' $\mathrm{Ilm}$ )}

Sejak masa Rasulullah pembelajaran hadis sudah dilakukan. Banyak riwayat yang menerangkan bahwa Rasulullah sering duduk dalam halaqah (kelompok orang-orang yang duduk melingkar) bersama sahabat untuk mengajar mereka. ${ }^{29}$ Jadi, sebagian sahabat yang menulis hadis ketika Nabi Saw masih hidup. selain itu, sahabat juga selalu menghafal dan mengingatingat kembali hadis tersebut, baik sendiri-sendiri atau berkelompok.

${ }^{27}$ Sya'roni, Otentisitas Hadis Menurut Ahli Hadis dan Kaum Sufi, h.1.

${ }^{28}$ Azami M.M, Hadis Nabawi dan Sejarah Kodifikasinya, h.106-107.

${ }^{29}$ Azami M.M, h.445. 
Pada masa tabiin kitab-kitab hadis sudah mulai muncul, yang materinya diambil dari kuliah para sahabat, menurut Azami kitab yang ditulis tabiin itu adalah kitab Basyir bin Nahik dan Hammam bin Munabbih, murid dari Abu Hurairah dan kitab-kitab milik Zaid bin Tsabit, Abdullah bin Abbas, Jabir bin Abdullah, dan lain-lain muncul pada periode ini.

Sejak perempat ketiga abad pertama, ahli hadis sudah menggunakan metode atraf, yaitu menulis pangkal suatu hadis sebagai petunjuk kepada materi hadis seluruhnya. Yang pertama kali memakai metode ini adalah Ibnu Sirin, ${ }^{30}$ kemudian metode ini diikuti Ismail bin Ayyasy, Hammad bin Sulaiman, Sufyan al-Tsauri, Ubaidullah bin Umar, Malik bin Anas,Waki', dan Yazid bin Zurai'.

3. Hadis Nabawi dan Otentitasnya

Pada dasarnya menurut M.M Azami ada tiga cara yang ditempuh dalam mengkritik hadis, agar dapat diketahui otentitasnya, yakni sebagai berikut:

a) Karakter Para Periwayat

Sebagaimana yang kita ketahui ada beberapa kriteria untuk para periwayat agar hadis yang diriwayatkannya dinyatakan Shahih, ketentuan tersebut antara lain:

1) Periwayat yang dipercaya haruslah ' $a d l$

Menurut Ibn al-Mubarak perawi yang adil adalah orang yang selalu salat berjamaah, tidak meminum nabidz (minuman beralkohol), tidak pernah melanggar hukum dalam hidupnya, tidak pernah berbohong, dan tidak mengidap penyakit mental. ${ }^{31}$

Untuk mengetahui 'adl tidaknya seorang perawi ada dua hal yang bisa dilakukan, yaitu pernyataan dari orang yang 'adl dan perawi tersebut memang terkenal dengan sifat 'adlnya. Semua perawi harus diteliti sifat 'adlnya kecuali para sahabat Nabi yang sudah tidak diragukan lagi sifat-sifatnya. Muhadditsin sepakat bahwa pada masa

\footnotetext{
${ }^{30}$ Azami M.M, h.451-452.

${ }^{31}$ Azami M.M, Menguji Keaslian Hadis-hadis Hukum, h.157.
} 
Rasulullah hidup dan masa Khalifaurrasyidin adalah masa berkumpulnya perawi yang adil.

2) Kapasitas intelektual perawi (dhabit)

Perawi yang dhabit adalah perawi yang hafal dengan sempurna hadis yang diterimanya; mampu menyampaikan hadis tersebut kepada orang lain; dan mampu memahami hadis yang dihafal tersebut. ${ }^{32}$

Dari sudut hafalan dhabith terbagi dua yaitu; pertama, dhabth shadri yakni hadis yang diterima terpelihara dalam hafalan secara sempurna sejak diterima sampai diriwayatkan kepada orang lain, kapan saja diperlukan hadis tersebut dapat diriwayatkan dengan sempurna, yang kedua, dhabth kitabi yaitu terpelihara periwayatan melalui tulisantulisan yang dimiliki. Perawi mengingat dengan baik catatan hadisnya, dan meriwayatkan hadis tersebut kepada orang lain dengan benar. ${ }^{33}$

b) Perbandingan Tekstual

Jika penelitian tertuju pada teks atau dokumen, metode yang digunakan adalah perbandingan atau pertanyaan pancingan dan referensi silang. Dengan mengumpulkan semua materi yang berhubungan, atau dengan kata lain semua hadis yang diteliti, kemudian membandingkannya satu sama lain dengan hati-hati, kemudian menentukan yang mana yang akurat.

Metode perbandingan bisa dilakukan dengan beberapa cara, yakni sebagai berikut:

1) Membandingkan hadis-hadis dari murid-murid yang berbeda tetapi masih dari ulama yang sama.

2) Membandingkan pernyataan-pernyataan yang dibuat pada waktu yang berbeda oleh seorang ulama.

3) Membandingkan versi lisan dan tulisan.

${ }^{32}$ Suryadi dan Suryadilaga, Metodologi Penelitian Hadis, h.104.

${ }^{33}$ Sya'roni, Otentisitas Hadis Menurut Ahli Hadis dan Kaum Sufi, h.36-37. 
4) Membandingkan hadis dengan teks yang berkaitan dalam alquran. ${ }^{34}$ c) Kritik Nalar

Menurut al-Mu'allami Al-Yamani penggunaan nalar ('aql) diterapkan dalam tiap tahap baik ketika mempelajari dan mengajarkan hadis, dalam menilai periwayat, dan dalam mengevaluasi otentisitas hadis.

Menurut Ibn Abi Hatim Al-Razi, inti dari pengujian nalar adalah bahwa hadis harus bernilai sebagai pernyataan dari Nabi saw. Beliau berkata: "Otentisitas hadis dapat diketahui dari datangnya hadis itu dari para periwayat yang terpercaya dan pernyataan itu sendiri harus memiliki nilai sebagai pernyataan kenabian. ${ }^{35}$

Inilah sebagian cara yang diterapkan oleh para ulama dalam mengevaluasi hadis-hadis secara rasional ditambah dengan kritik isnad, agar dapat dipastikan bahwa literatur hadis diriwayatkan dalam bentuk semurni mungkin dan dapat menyingkirkan hal-hal yang mencurigakan. Oleh karena itu, sebagai seorang muslim yang baik terlebih lagi jika berprofesi sebagai da'i atau sebagai pendidik hendaknya kita benar-benar mempelajari hadis sebagai sumber hukum kedua setelah alquran, agar hadis yang kita sampaikan benar-benar hadis yang otentik dan dapat dipertanggungjawabkan.

\section{E. Kesimpulan}

Berdasarkan pandangan-pandangan yang telah dipaparkan tersebut, tampak bahwa Goldziher memiliki sikap kritis terhadap otentisitas hadis Nabi dengan berbagai argumentasi yang ia ajukan. Akan tetapi, dalam pandangannya Goldziher hanya fokus pada satu riwayat saja dan kurang mempertimbangkan riwayat lain tentang hadis keutamaan tiga masjid tersebut. Apakah beberapa riwayat tersebut juga diragukan kredibilitasnya? Ataukah matan hadis yang diriwayatkan oleh mereka juga pesanan politikus pada zamannya? Di sini terlihat dengan jelas ke-kurang teliti-an seorang Goldziher dalam melakukan

\footnotetext{
${ }^{34}$ Azami M.M, Menguji Keaslian Hadis-hadis Hukum, h.158.

${ }^{35}$ Azami M.M, h.161.
} 
penelitian ilmiah yang pada hadis ini yang hanya fokus pada satu obyek dengan meniadakan obyek yang lain.

Menurut Goldziher, hadis sebagai corpus yang berisikan perkataan, perbuatan, dan taqrir Nabi Saw. jika dilihat dari sejarah perkembangannya kerap berbaur dengan berbagai kepentingan terutama politik. Menurutnya, secara ilmiah akan sulit diterima bahwa suatu hadis adalah otentik dan orisinil dari Nabi Saw, mengingat rentang waktu yang lama antara wafatnya Nabi dengan masa kodifikasi hadis.

Tetapi, menurut hemat penulis apabila goldziher yang mengatakan bahwa periwayat hadis (Az-Zuhri) telah memalsukan hadis ini, menurut saya kurang tepat, karena perawi hadis tentang tiga masjid tersebut bukan hanya AzZuhri, selain dia, ada rawi-rawi yang lain yang dapat dipercaya, yang meriwayatkan hadis tersebut, antara lain: ${ }^{36}$

1. 'Abd al-Malik bin 'Umair.

2. Qasim

3. Qatadah

4. Ibrahim bin Sahl

5. Qushaim

6. Mujalid

7. 'Abd al-Hamid

8. Laits

9. 'Abd al-Malik bin 'Umair

10. Aban bin Tsa'labah

11. 'Abd al-Malik

12. Yazid bin Abu Habib

13. Hisyam

14. Salamah bin Kuhail

15. Yazid bin Abu Maryam

${ }^{36}$ Azami M.M, Hadis Nabawi dan Sejarah Kodifikasinya, h.612. 
Syarifuddin, Moh. Zaiful Rosyid: Persoalan Otentisitas Hadis Perspektif Ignaz Golziher

16. Muhammad bin Ibrahim

17. Muhammad bin 'Amr

18. 'Imran bin Abu Anas

19. Al-Zuhri. 
Syarifuddin, Moh. Zaiful Rosyid: Persoalan Otentisitas Hadis Perspektif Ignaz Golziher

\section{Daftar Pustaka}

A. Mannan Buchari. Menyingkap Tabir Orientalisme. Jakarta: Amzah, 2006.

Ali, Masrur. Teori Common Link G.H.A. Juynboll: Melacak Akar Kesejarahan Hadits. Yogyakarta: LKiS, 2007.

AlMakin. Antara Barat dan Timur. Jakarta: Serambi Ilmu Semesta, 2015.

Arif, Syamsuddin. Orientalis \& diabolisme pemikiran. Gema Insani, 2008.

Artawijaya. Jaringan Yahudi Internasional di Nusantara. Pustaka Al Kautsar, 2010.

Azami M.M. Dirasah fi al-Hadits an-Nabawi wa Tarikh Tadwinih. Riyadl: alMaktab al-Islami, 1980.

—. Hadis Nabawi dan Sejarah Kodifikasinya. Diterjemahkan oleh Ali Mustofa Yaqub. Jakarta: Pustaka Firdaus, 2014.

—. Menguji Keaslian Hadis-hadis Hukum. Jakarta: Pustaka Firdaus, 2004.

Hati-hati!! Bahaya Tokoh ORIENTALIS - Ustadz Adi Hidayat. Diakses 9 September 2019. https://www.youtube.com/watch?v=FGrN38u3hEE.

Herfin Fahri. "Kontroversi Tentang Otentisitas Hadits.” Al-Hikmah Jurnal Studi Keislaman, 1, 4 (Maret 2014).

Idri. Hadis dan Orientalis: Perspektif Ulama Hadis dan Orientalis Tentang Hadis Nabi. Depok: Kencana, 2017.

Isa H.A. Salam, dan Bustamin (last). Metodologi Kritik Hadis. Jakarta: Raja Grafindo Persada, 2004.

Muhammad, Ajaj Al-Khatib. Hadis Nabi Sebelum Dibukukan. Jakarta: Gema Insani Press, 1999. 
Syarifuddin, Moh. Zaiful Rosyid: Persoalan Otentisitas Hadis Perspektif Ignaz Golziher

Mustofa Yaqub, Ali. Kritik Hadits. Jakarta: Pustaka Firdaus, 1995.

Suryadi, dan Alfatih Suryadilaga. Metodologi Penelitian Hadis. Yogyakarta: Teras, 2009.

Sya'roni, Usman. Otentisitas Hadis Menurut Ahli Hadis dan Kaum Sufi. Jakarta: Pustaka Firdaus, 2002.

Zainuddin. "Persoalan Otentisitas Hadits." Jurnal Qolamuna, 2, 1 (Februari 2006). 
Syarifuddin, Moh. Zaiful Rosyid: Persoalan Otentisitas Hadis Perspektif Ignaz Golziher 